\title{
Publisher Correction: Neuronal deletion of Gtf2i, associated with Williams syndrome, causes behavioral and myelin alterations rescuable by a remyelinating drug
}

Boaz Barak (D), Zicong Zhang, Yuanyuan Liu, Ariel Nir, Sari S. Trangle, Michaela Ennis Di, Kirsten M. Levandowski,

Dongqing Wang, Kathleen Quast, Gabriella L. Boulting, Yi Li, Dashzeveg Bayarsaihan, Zhigang He (D) and Guoping Feng (D)

Correction to: Nature Neuroscience https://doi.org/10.1038/s41593-019-0380-9, published online 22 April 2019.

In the version of this article initially published, the $y$-axis labels in Figs. 5a and 6e should have read Olig2 ${ }^{+}+\mathrm{CC}^{+}$. The error has been corrected in the HTML and PDF versions of the article.

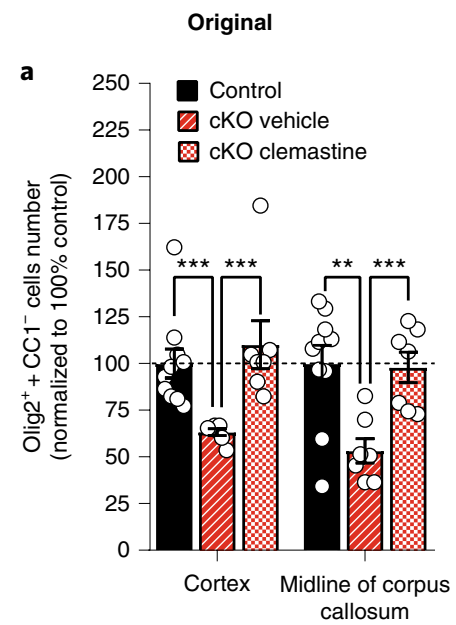

Fig. 5 | Orginal and Corrected.

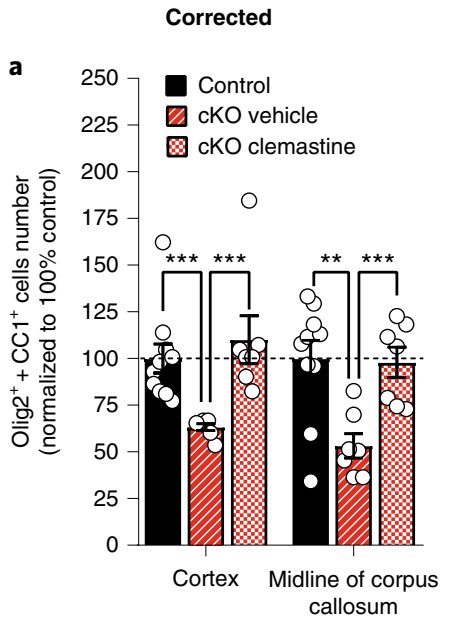

Corrected

e

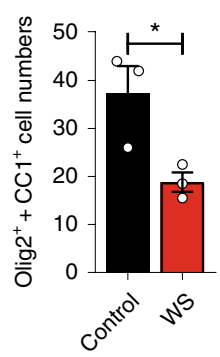

Fig. 6 | Orginal and Corrected. 